\title{
Pt-20Rh dispersion strengthened by ZrO2 - Microstructure and strength
}

Hu, Faping; Yu, Tianbo; Liu, Weiting; Yang, Yan; Wei, Guobing; Luo, Xuan; Tang, Huiyi; Hansen, Niels; Huang, Xiaoxu; Xie, Weidong

Published in:

Materials Science and Engineering $A$

Link to article, DOI:

10.1016/j.msea.2019.138305

Publication date:

2019

Document Version

Peer reviewed version

Link back to DTU Orbit

Citation (APA):

Hu, F., Yu, T., Liu, W., Yang, Y., Wei, G., Luo, X., Tang, H., Hansen, N., Huang, X., \& Xie, W. (2019). Pt-20Rh dispersion strengthened by ZrO' - Microstructure and strength. Materials Science and Engineering A, 765, [138305]. https://doi.org/10.1016/j.msea.2019.138305

\section{General rights}

Copyright and moral rights for the publications made accessible in the public portal are retained by the authors and/or other copyright owners and it is a condition of accessing publications that users recognise and abide by the legal requirements associated with these rights.

- Users may download and print one copy of any publication from the public portal for the purpose of private study or research.

- You may not further distribute the material or use it for any profit-making activity or commercial gain

- You may freely distribute the URL identifying the publication in the public portal 


\section{Pt-20Rh dispersion strengthened by $\mathrm{ZrO}_{2}$ - microstructure and strength}

Faping $\mathrm{Hu}^{\mathrm{a}}$, Tianbo $\mathrm{Yu}^{\mathrm{b}}$, Weiting Liu ${ }^{\mathrm{c}}$, Yan Yang ${ }^{\mathrm{a}}$, Guobing $\mathrm{Wei}^{\mathrm{a}}$, Xuan Luo ${ }^{\mathrm{a}}$, Huiyi Tang ${ }^{\mathrm{d}}$, Niels Hansen $^{\mathrm{a}, \mathrm{e}}$, Xiaoxu Huang ${ }^{\mathrm{a}, \mathrm{b}}$, Weidong $\mathrm{Xie}^{\mathrm{a}^{*}}$

a Joint International Laboratory for Light Alloys (MOE), College of Materials Science and Engineering, Chongqing University, Chongqing, 400044, China;

${ }^{\mathrm{b}}$ Department of Mechanical Engineering, Technical University of Denmark, DK-2800, Kgs. Lyngby, Denmark

${ }^{\mathrm{C}}$ Chongqing Polycomp International Corporation, Chongqing 400044, China

${ }^{\mathrm{d}}$ Chongqing Materials Research Institute Co. Ltd, Chongqing 400044, China

${ }^{\mathrm{e}}$ Technical University of Denmark, Risø Campus, DK-4000 Roskilde, Denmark

Abstract: Pt-20Rh dispersion strengthened by $\mathrm{ZrO}_{2}$ particles in different volume fractions has been produced by consolidation of milled powder which has been internally oxidized. The microstructure has been characterized by scanning electron microscopy, electron backscatter diffraction, and transmission electron microscopy; tensile properties have been determined at RT and $1000{ }^{\circ} \mathrm{C}$. The Pt-20Rh matrix is subdivided on the submicrometer scale by low angle dislocation boundaries and high angle boundaries. $\mathrm{ZrO}_{2}$ particles with sizes in the range 5-35 nm are uniformly distributed and with increasing volume fraction the flow stress increases and at $0.9 \%$ it is doubled both at RT and at $1000{ }^{\circ} \mathrm{C}$. Based on the superposition of particle and matrix strengthening, the flow stress has been calculated and good accord has been found with experiment both at RT and $1000{ }^{\circ} \mathrm{C}$.

Keywords: Pt, $\mathrm{ZrO}_{2}$, dispersion strengthening, Orowan stress, internal oxidation- powder metallurgy

\section{Introduction}

Platinum and platinum alloys are used in jewelry, but they play a crucial or even irreplaceable role in some industrial fields e. g. glass industry, space technology and chemical synthesis (as a catalyst) because of their excellent and unusual properties ${ }^{[1-3]}$. In the glass industry, for example production of glass fiber, platinum products (as shown in Fig. 1) work in the extremely aggressive environments such as a high temperature (1100-1400 $\left.{ }^{\circ} \mathrm{C}\right)$, an oxidizing atmosphere, a corrosive glass melt and an alternating stress (1-40 MPa) for a long time (over a year) ${ }^{[1,3,4]}$. Pure platinum

\footnotetext{
* Corresponding authors.

E-mail address: wdxie@cqu.edu.cn (W. D. Xie).
} 
metal is soft and unstable for high-temperature applications ${ }^{[4,5]}$. Solid solution strengthening and oxide dispersion strengthening are two methods in common use to strengthen the metals at elevated temperatures ${ }^{[6-9]}$. This material design is benefitted from the high melting temperature of platinum and its well established corrosion resistance. As a consequence industrial material have been developed by several companies marketing Pt-Rh- $\mathrm{ZrO}_{2}$ which can meet demands of high strength and durability. These demands are motivated by the expensive manufacturing equipment and expensive unwanted shut-downs.

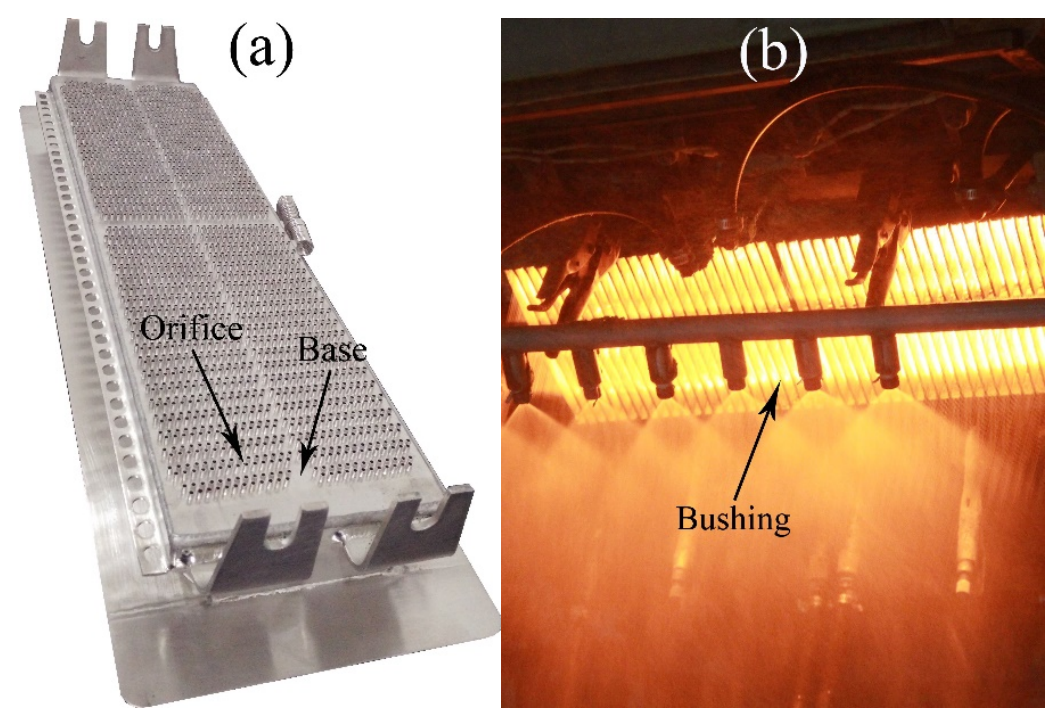

Fig. 1. (a) A platinum-alloy bushing and (b) its work environment during continuous fiber glass manufacturing. To construct this bushing the orifice and the base are fabricated separately, followed by a manual melting welding.

In the present study we apply both strengthening mechanisms by alloying with $20 \mathrm{wt} \% \mathrm{Rh}$ to introduce high efficient solution strengthening ${ }^{[1,10]}$ and by internal oxidation of a Pt-Rh-Zr alloy to form a dispersion of hard $\mathrm{ZrO}_{2}$ nanoparticles. To obtain a homogeneous structure with a narrow particle distribution we in accordance with previous studies apply consolidation of milled powder which is internally oxidized before final steps of cold rolling and high temperature annealing at $1150{ }^{\circ} \mathrm{C}{ }^{[11]}$. By the combination of thermomechanical process, we add matrix strengthening to the solid solution and particle strengthening. The superposition of three mechanisms is studied by tensile testing at RT and at high temperature. In a following analysis the experimental strength is compared with the strength estimated based on quantification of microstructural parameters.

\section{Materials and methods}


The composition experimentally measured by ICP-AES (JARRELLASH Autoscan Advantage), and nominal composition (in bracket) of investigated alloys are listed in Table $1^{[11]}$. The processing steps ${ }^{[11]}$ are shown in Fig. 2 and can be briefly summarized in the following: Pt-20Rh-0.01Y-(0, 0.05, 0.1 and 0.3 ) $\mathrm{Zr}$ (wt\%) cast ingots (8 kilograms for each ingot), produced by high-frequency induction melting of high purity (99.5\%) Pt, Rh, Y and $\mathrm{Zr}$ metals at $1950{ }^{\circ} \mathrm{C}$ under argon atmosphere, were disintegrated and milled to fine powder. The powder was sintered into a loose and porous structure to internally oxidize at $1150{ }^{\circ} \mathrm{C}$ in air for 4 hours where the Zr was relatively sufficiently oxidized while the loss of platinum metals was acceptable ${ }^{[12]}$. In a next step, the billets were hot forged at $1400{ }^{\circ} \mathrm{C}$ to $30 \mathrm{~mm}$ thick plates which were rolled to $1 \mathrm{~mm}$ (equivalent strain is about 3.9) sheets at RT followed by annealing at $1150{ }^{\circ} \mathrm{C}$ for $30 \mathrm{~min}$. The $\mathrm{Zr}$ atoms can be oxidized into $\mathrm{ZrO}_{2}$ during internal oxidation or even processing steps such as sintering and hot forging ${ }^{[4,6]}$. However, exposing sintered Pt-Rh-Zr to high temperature air (internal oxidation) is necessary to oxidize the $\mathrm{Zr}$ adequately due to the extremely low solubility of oxygen atoms in Pt-Rh. From the thin sheets, perforated dies were produced by punching for industrial use. For preparation of test specimens the sheets were machined into a dog-bone shape (The gauge section was $20 \mathrm{~mm}, 10 \mathrm{~mm}$ and $1 \mathrm{~mm}$ in length, width and thickness, respectively) along the rolling direction to conduct tensile tests with an initial strain rate of $8.3 \cdot 10^{-3} s^{-1}$ at RT and of $8.3 \cdot 10^{-5} S^{-1}$ at $1000{ }^{\circ} \mathrm{C}$. Engineering stress $\left(\sigma_{E}\right)$ and strain $\left(\varepsilon_{E}\right)$ were calculated based on the load force, the change of length in the gauge section and the initial sample size, while true stress ( $\left.\sigma_{T}\right)$ and true strain $\left(\varepsilon_{T}\right)$ were obtained, based on the equations $\sigma_{T}=\sigma_{E}\left(1+\varepsilon_{E}\right)$ and $\varepsilon_{T}=$ $\ln \left(1+\varepsilon_{E}\right)$, respectively. In order to avoid the influences of necking, only the $\sigma_{E}$ lower than ultimate tensile strength (UTS) and corresponding strain values were used for the calculation of $\sigma_{T}$ and $\varepsilon_{T}$. The processing was carried out at Chongqing International Composite Materials Co., LTD. For simplicity, the alloys were dubbed A (0 wt\%Zr), B (0.05 wt\%Zr), C (0.09 wt\%Zr) and D (0.263 wt\%Zr).

Table 1. Experimentally measured composition and nominal composition (in bracket) of the investigated alloys (in weight \%).

\begin{tabular}{llllll}
\hline Alloys & $\mathrm{Zr}$ & $\mathrm{Y}$ & $\mathrm{Rh}$ & Others & Pt \\
\hline A & - & $0.010(0.015)$ & $20.00(20)$ & $\leq 0.01$ & Bal. \\
B & $0.05(0.05)$ & $0.011(0.015)$ & $19.70(20)$ & $\leq 0.01$ & Bal. \\
C & $0.09(0.10)$ & $0.011(0.015)$ & $20.29(20)$ & $\leq 0.01$ & Bal. \\
\hline
\end{tabular}




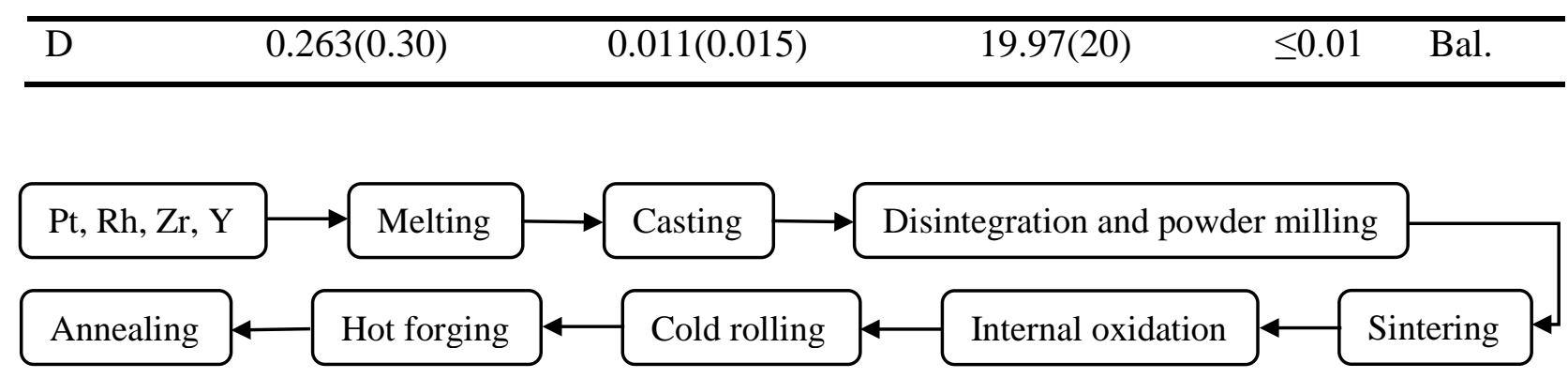

Fig. 2. Processing steps used in industry and for preparation of test samples.

The microstructure was examined by transmission electron microscopy (TEM) at $200 \mathrm{kV}$ (JEOL JEM-2100) and at $300 \mathrm{kV}$ (JEOL JEM-3000F), supplemented by electron backscatter diffraction (EBSD) in a scanning electron microscope (Zeiss Supra 35). The composition of $\mathrm{ZrO}_{2}$ particles was investigated by energy dispersive X-ray spectroscopy (EDS) in JEM-2100. EBSD was applied to characterize the matrix structure with a step size of $180 \mathrm{~nm}$ and TEM/HRTEM to analyze the size of $\mathrm{ZrO}_{2}$ particles and their crystallography. The samples for TEM/HRTEM were cold rolled to 90\% in thickness followed by an annealing at $1150{ }^{\circ} \mathrm{C}$ for $20 \mathrm{~min}$, mechanical grinding and $\mathrm{Ar}^{+}$ion milling. This treatment can significantly offset the matrix structure without affecting the oxide particles.

As will be shown in the following the four samples (A, B, C and D) have a comparable microstructure with the exception of the volume concentration of $\mathrm{ZrO}_{2}$ particles. The structural characterization therefore has been limited to EBSD for sample A and transmission electron microscopy for sample A, C and D.

\section{Results}

\subsection{Mechanical properties}

Fig. 3 shows the stress - strain curves of investigated specimens and corresponding work hardening rate $\left(=\mathrm{d} \sigma_{T} / \mathrm{d} \varepsilon_{T}\right)$ curves at $\mathrm{RT}$ and $1000{ }^{\circ} \mathrm{C}$. The true stress - true strain curves are only plotted for the parts before reaching UTS in order to avoid the influence of necking. At RT, the yield stress $\left(\sigma_{0.2}\right)$ at $0.2 \%$ offset and UTS have significantly increased accompanied by a slight reduction in elongation with increasing $\mathrm{Zr}$ concentration (Fig. 3a and b). The yield stress $\left(\sigma_{0.2}\right)$ of sample D containing $0.263 w t \% \mathrm{Zr}$ is $257 \mathrm{MPa}$, which is about twice of that for sample A without $\mathrm{Zr}$, as listed in Table 2. The work hardening rate of particle strengthened samples, as shown in Fig. 3c, increases with increasing volume concentration of dispersed particles, a typical particle dispersion strengthening behavior. The strength at $1000{ }^{\circ} \mathrm{C}$ also significantly increases with increasing $\mathrm{Zr}$ 
concentration and $\sigma_{0.2}$ of sample $\mathrm{D}$ is about twice that of sample A. However, the work hardening rate is small for all samples at a true strain above 0.05, when compared with the hardening at RT. The tensile data are summarized in Table 2.
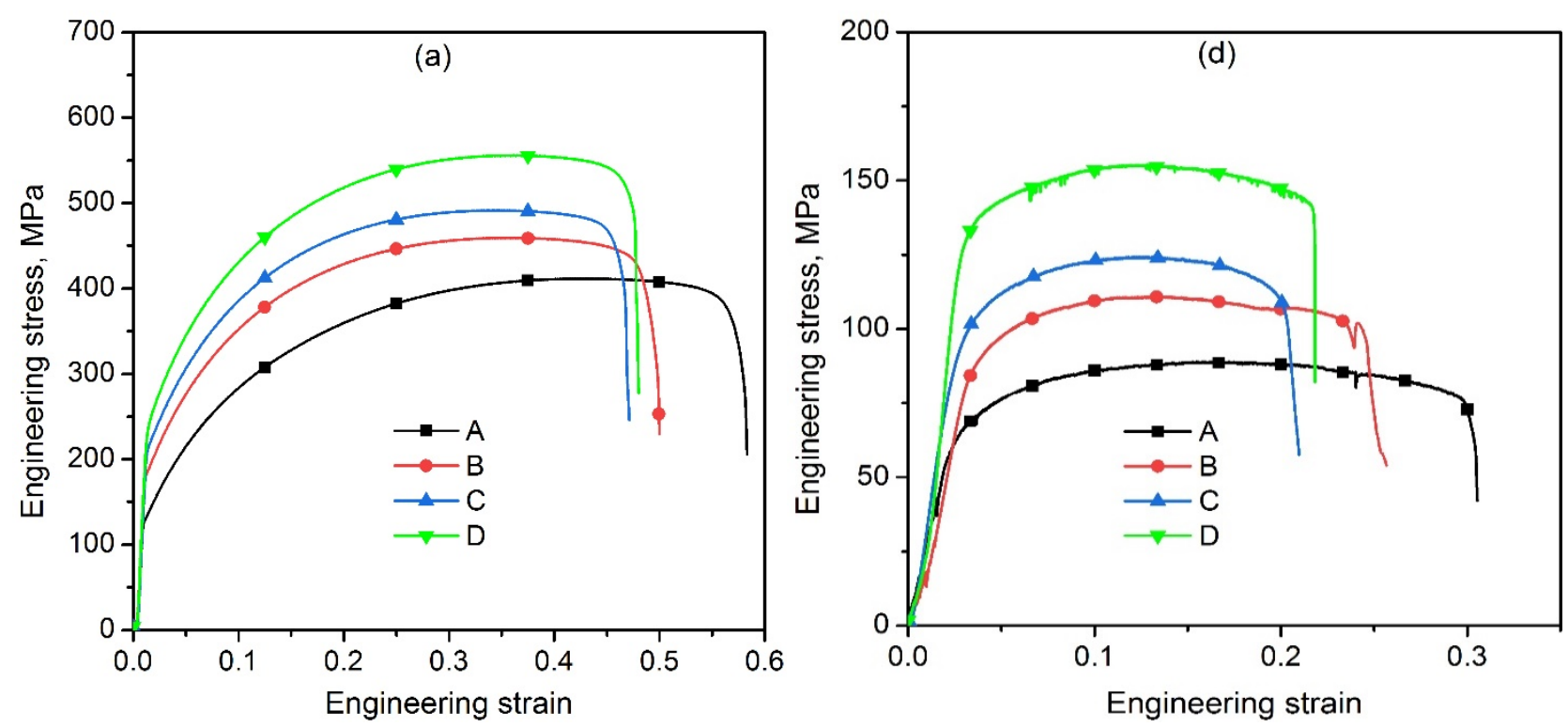

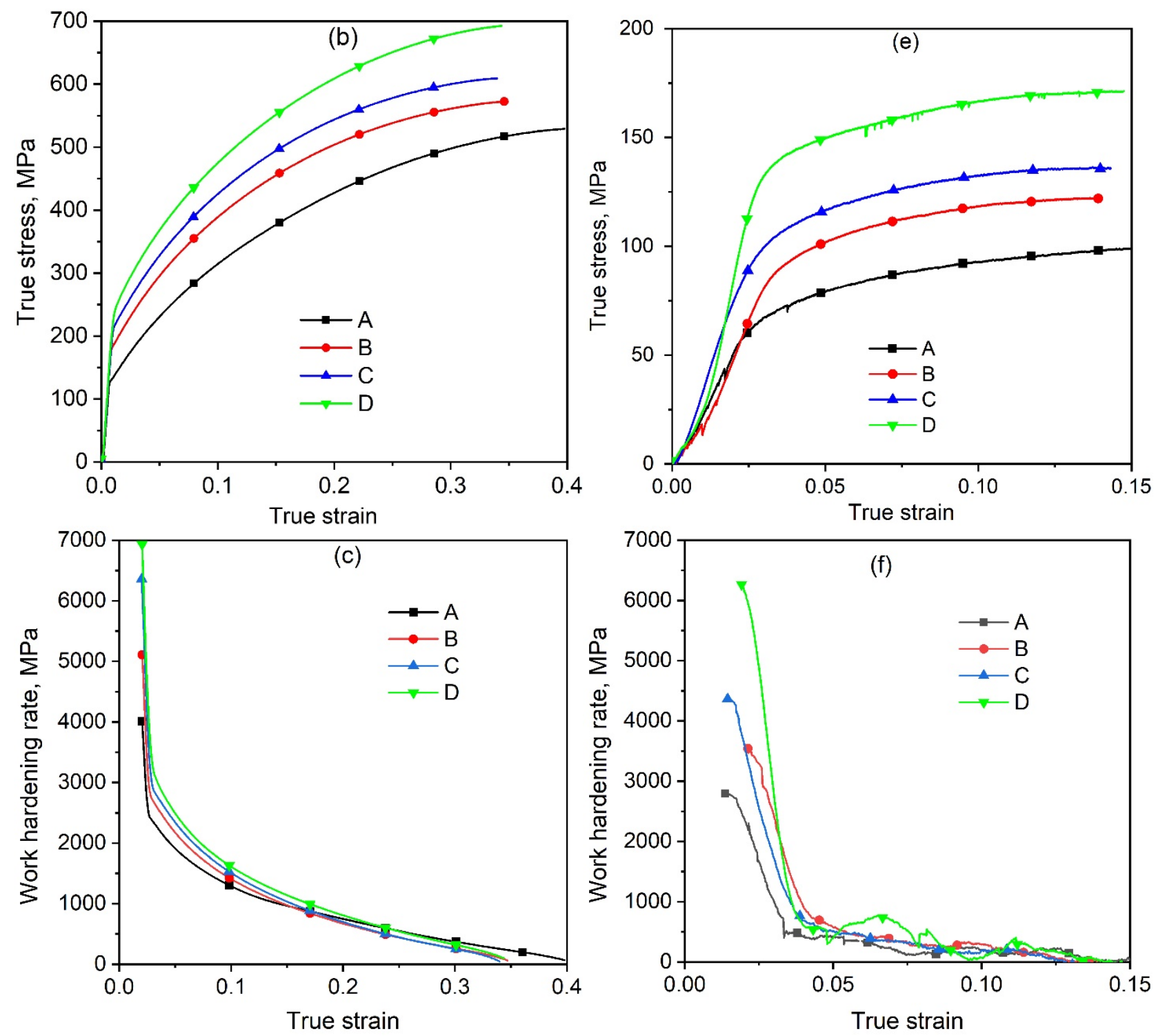

Fig. 3. The results of the tensile tests. Engineering stress-strain curves (a), true stress-strain curves (b) and work hardening rate (c) at RT. Engineering stress-strain curves (d), true stress-strain curves (e) and work hardening rate (f) at $1000{ }^{\circ} \mathrm{C}$.

Table 2. Summary of $\sigma_{0.2}$ and UTS at RT and at $1000^{\circ} \mathrm{C}(\mathrm{MPa})^{[10]}$.

\begin{tabular}{ccccc}
\hline Alloy & $\sigma_{0.2}$ at RT & UTS at RT & $\sigma_{0.2}$ at $1000^{\circ} \mathrm{C}$ & UTS at $1000{ }^{\circ} \mathrm{C}$ \\
\hline A & 143 & 411 & 67 & 91 \\
B & 200 & 459 & 89 & 114 \\
C & 228 & 491 & 99 & 137 \\
D & 257 & 555 & 124 & 152 \\
\hline
\end{tabular}

3.2 Microstructure of matrix 
Fig. 4 shows typical EBSD maps of sample A in the cold rolled and annealed condition (before tensile testing). The misorientation angle distribution shows that they are low angle boundaries (3$15^{\circ}$ ) and high angle boundaries $\left(>15^{\circ}\right)$. The latter are parallel to the RD.

The lamellar morphology and the fairly large boundary spacing point to a recovered structure not being recrystallized. This apparent stability of the A sample without $\mathrm{Zr}$ may have its cause in the content of Y present as yttria particles acting as stabilizers.
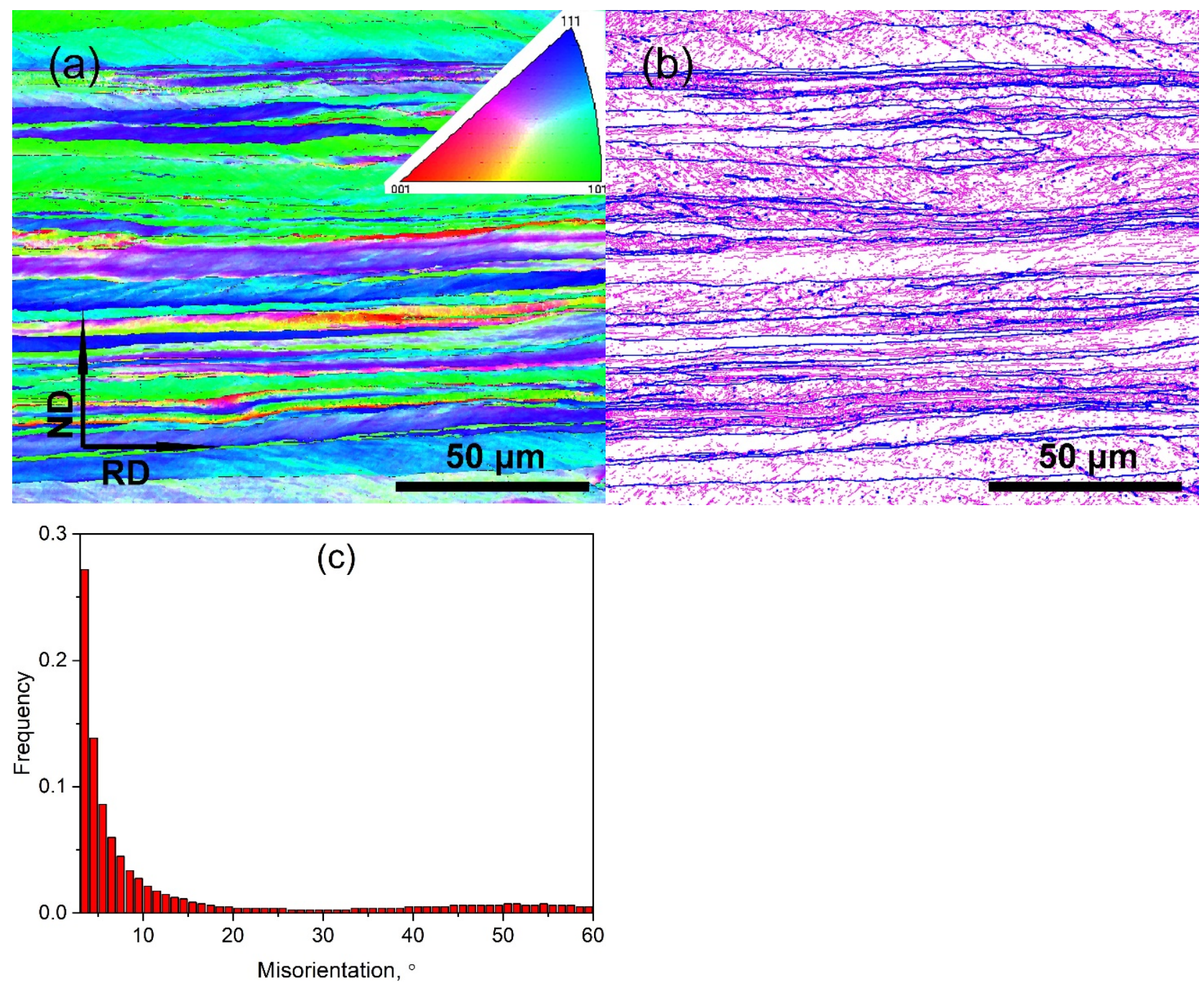

Fig. 4. EBSD maps of sample A: (a) Inverse pole figure coloring map, (b) corresponding boundary map (the red lines and blue lines indicate low angle boundaries between $3^{\circ}$ and $15^{\circ}$ and high angle boundaries larger than $15^{\circ}$, respectively) and (c) boundary misorientation angle distribution.

\subsection{Dispersed particles}

Fig. 5 shows some typical $\mathrm{ZrO}_{2}$ micrographs taken from sample $\mathrm{C}$ and $\mathrm{D}$. Particles are almost spherical and appear near-circular in the two-dimensional TEM images. Most particles are very fine 
and are distributed uniformly. Fig. 5d shows the EDS analysis results of the particle in Fig. 5c, showing the particle composition of zirconium and oxygen.
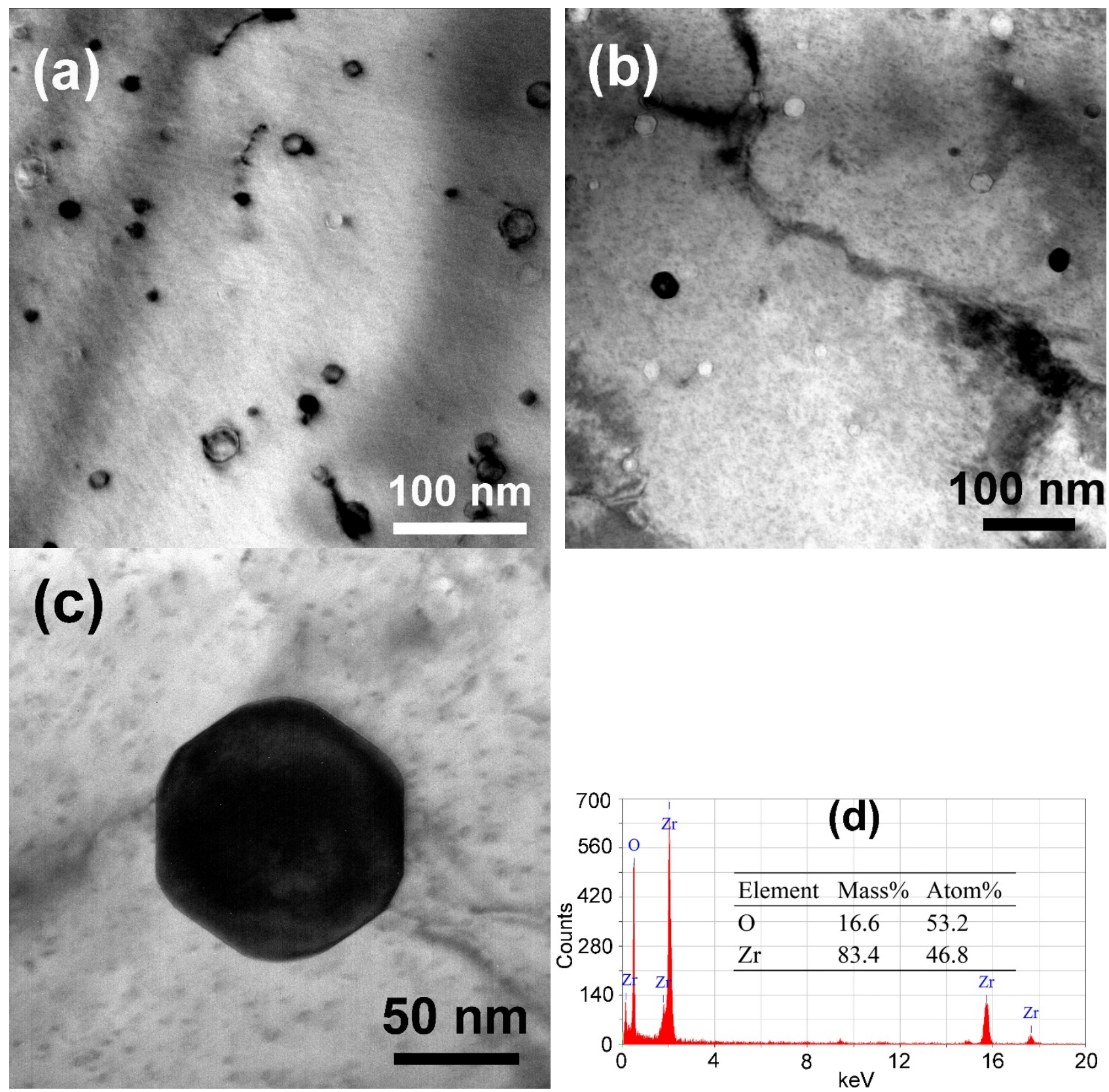

Fig. 5. TEM images and EDS analysis results of particles. Bright field TEM images of particles taken from sample C (a) and sample D (b and c). (d) EDS analysis results of the particle in Fig. 5c. Inset table shows the mass and atom percent for each element.

Spherical particles are also found in sample A (Fig. 6), though they are relatively few and fine. Fig. 6c indicates that the particle is mainly composed of $\mathrm{Y}$ and $\mathrm{O}$ elements possibly accompanied with Fe impurities (the Fe peak may come from the instrument itself). 

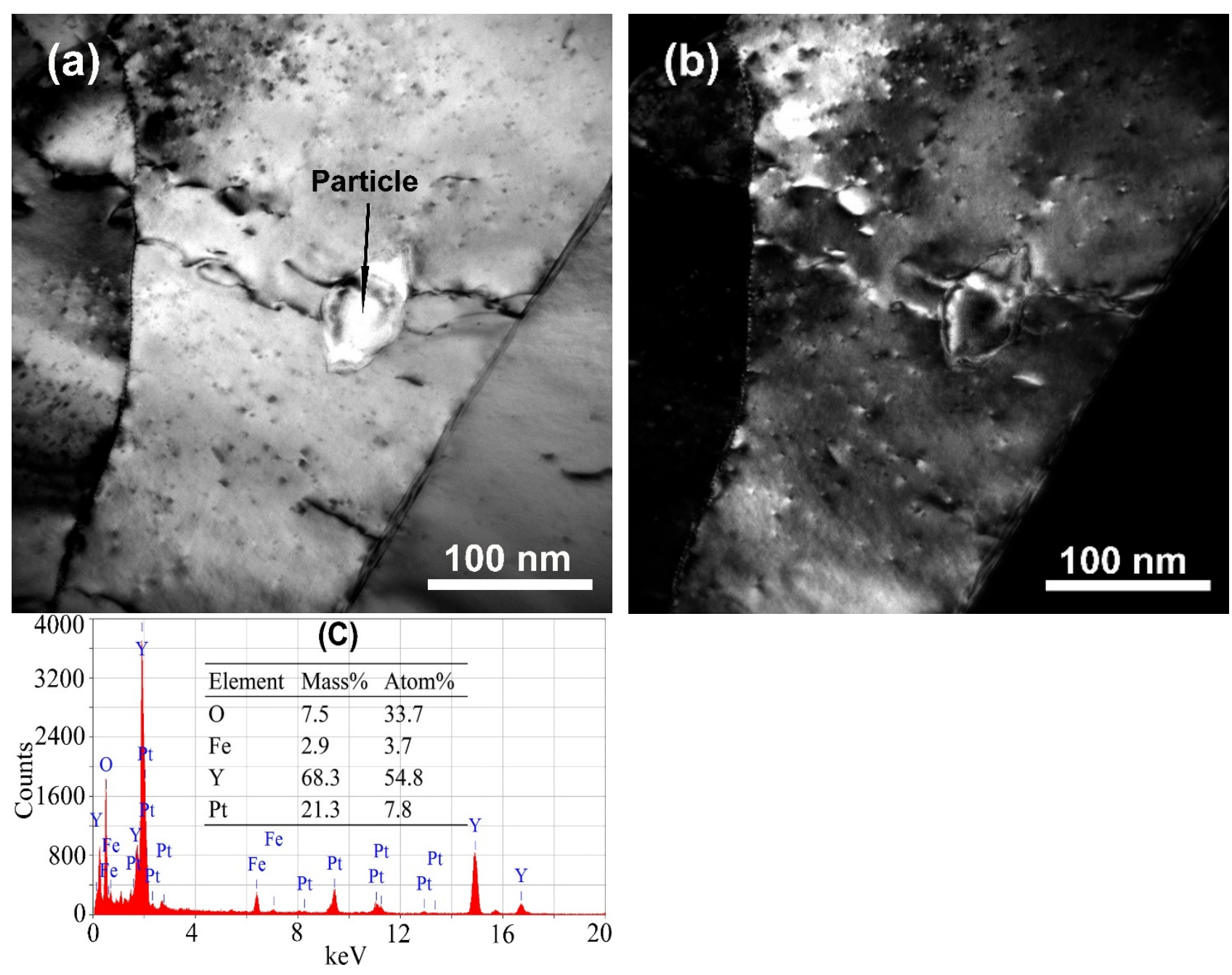

Fig. 6. TEM observations of an yttria particle. (a) Bright-field and (b) corresponding dark-field TEM images. (c) Corresponding EDS results of the particle in Fig. 6a. Inset table shows the mass and atom percent for each element.

The particles are difficult to characterize by selected area diffraction, owing to their small size. Thus, HRTEM was used to investigate the structure of the particles. The FFT diagrams from different zone axes (no less than three for each particle) were indexed according to the common $\mathrm{ZrO}_{2}$ structure ${ }^{[13,14]}$ and then the crystal structure was identified. Two types of $\mathrm{ZrO}_{2}$ crystal structure, i.e. monoclinic and tetragonal structures, were identified as shown in Fig. 7. 

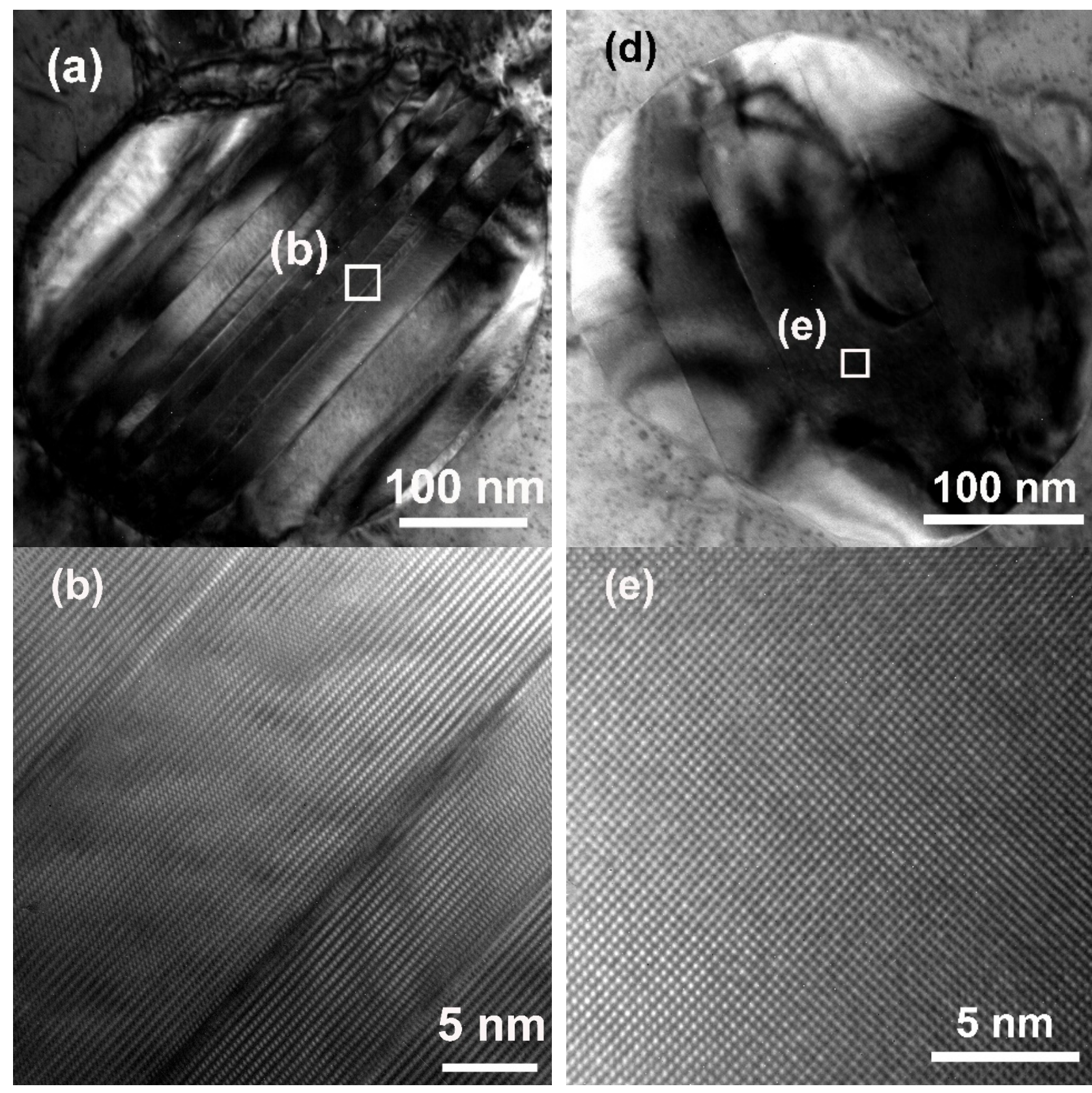

(b)

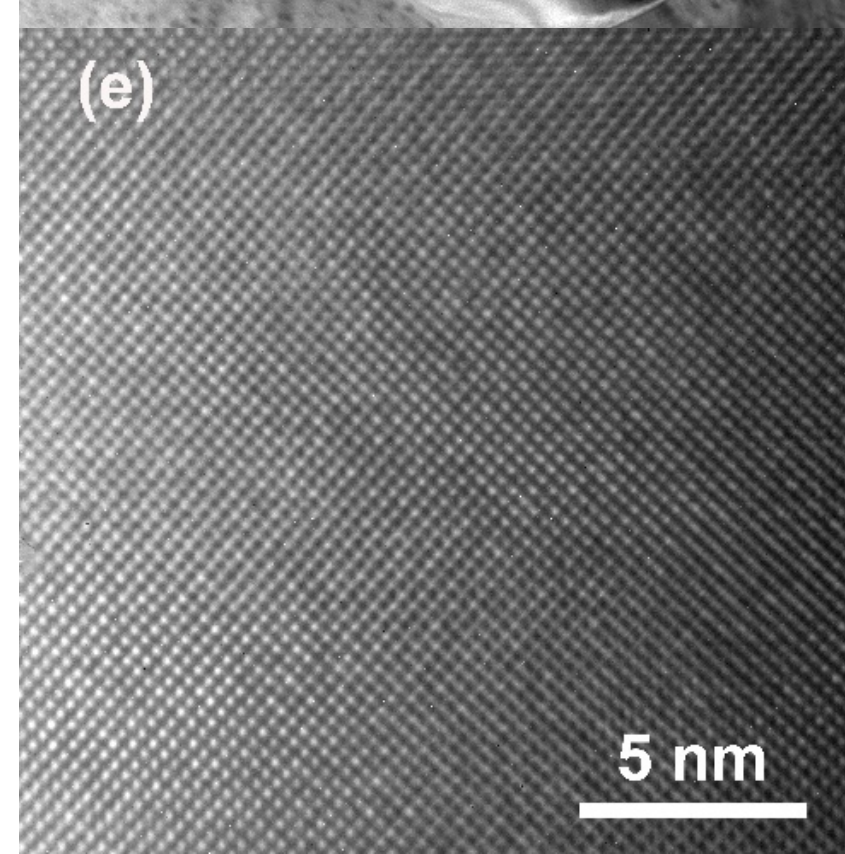




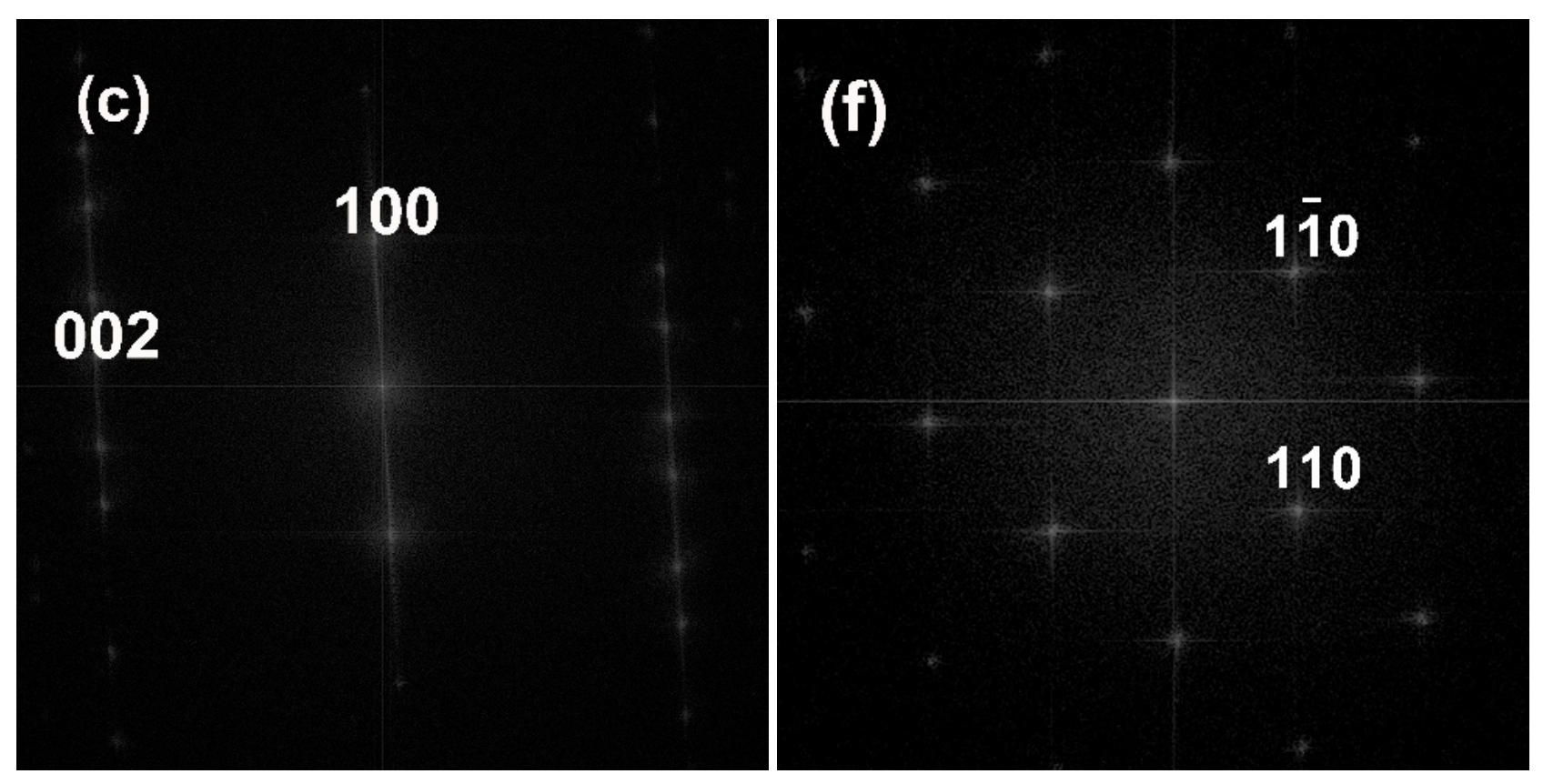

Fig. 7. TEM and HRTEM images of zirconia particles. (a) Bright-field image, (b) HRTEM image of the area indicated in (a) and (c) FFT diagram of a monoclinic particle with the electron beam approximately parallel to [010]. (d) Bright-field image, (e) HRTEM image of the area indicated in (d) and (f) FFT diagram of a tetragonal particle with the electron beam approximately parallel to [001].

Fig. 8 shows the diameter distribution of $\mathrm{ZrO}_{2}$ particles in a wide (a) and a narrow range (b). 161 and $212 \mathrm{ZrO}_{2}$ particles in TEM images were analyzed to evaluate the size distribution of sample C and sample D, respectively. The particle sizes of the two samples show a similar unimodal distribution and the diameters of most particles (more than 90 percent) are in the range from $5 \mathrm{~nm}$ to $35 \mathrm{~nm}$. Very few particles have sizes larger than $100 \mathrm{~nm}$, as shown in Fig. 8a. The particle size has not been determined in sample $B$, but it is assumed to be of the same order as the particles shown in Fig. 8. 

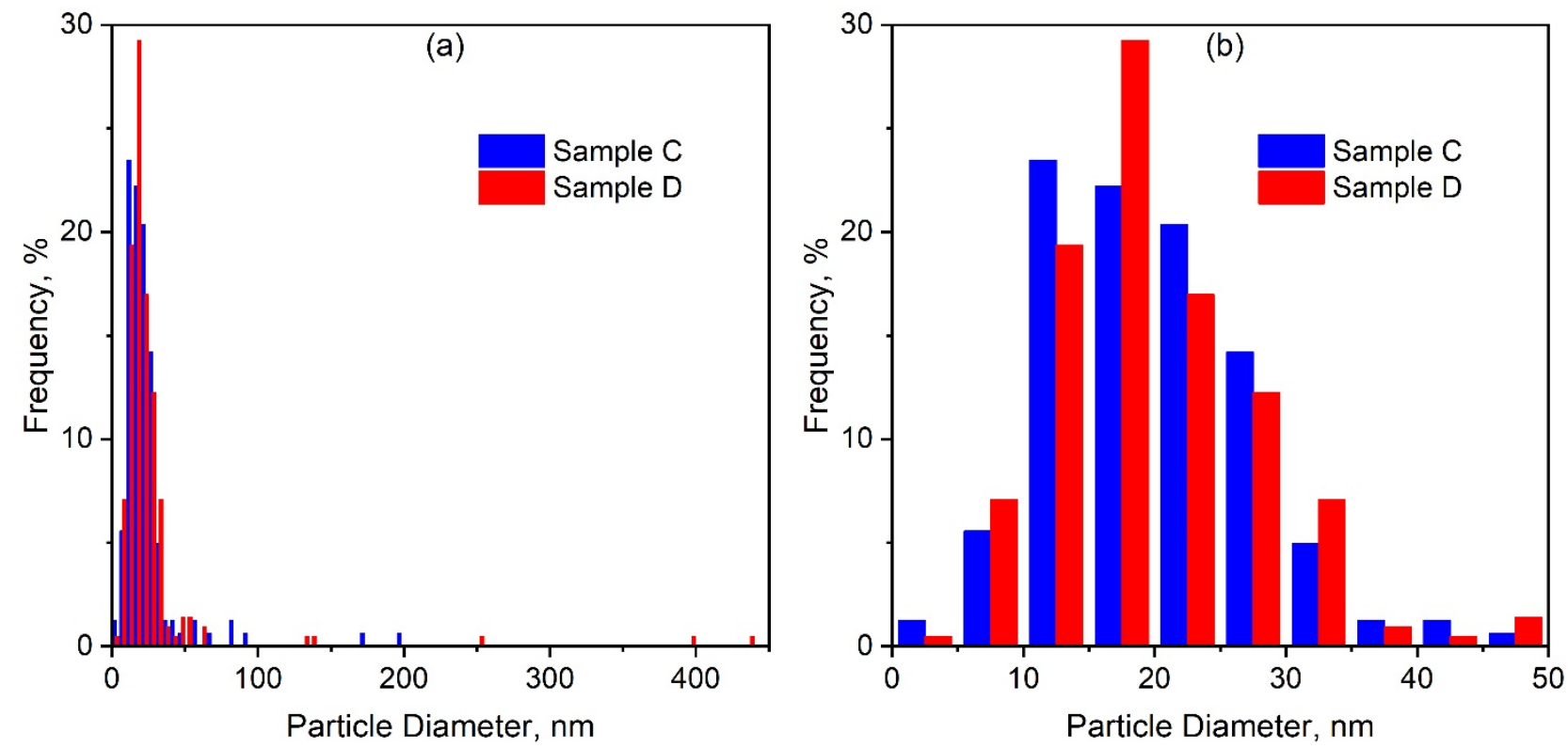

Fig. 8. Particle diameter distribution in sample $C$ and sample $D$ in a wide (a) and a narrow (b) range.

\section{Discussion}

\subsection{Dispersed particles}

$\mathrm{ZrO}_{2}$ has three different structures at atmospheric pressure, monoclinic $\left(\mathrm{m}-\mathrm{ZrO}_{2}\right)$ at $\mathrm{RT}$, tetragonal $\left(\mathrm{t}-\mathrm{ZrO}_{2}\right)$ between $1440 \mathrm{~K}$ and $2640 \mathrm{~K}$, and cubic $\left(\mathrm{c}-\mathrm{ZrO}_{2}\right)$ from $2640 \mathrm{~K}$ to the melting point ${ }^{[13,15]}$. The transformation from $\mathrm{t}-\mathrm{ZrO}_{2}$ to $\mathrm{m}-\mathrm{ZrO}_{2}$, accompanied by a volume expansion of 3-5\%, may cause catastrophic mechanical failure during cooling. Therefore, most engineering applications make use of tetragonal and cubic phases that can be stabilized down to RT by the addition of magnesia, calcia, yttria, or rare earth oxides ${ }^{[16]}$. Yttria is present in all samples and the presence of $\mathrm{t}-\mathrm{ZrO}_{2}$ is observed as expected.

Particles $\left(\mathrm{ZrO}_{2}\right)$ are observed in a unimodal distribution with an average diameter of about $25 \mathrm{~nm}$ as shown in Fig. 8. This is different from another dispersion hardened platinum material (platinum $\mathrm{DPH})^{[7,17]}$, where particles show a bimodal distribution. About $16 \%$ of the particles size in this previous study ranged from $25 \mathrm{~nm}$ to $150 \mathrm{~nm}$ with an average diameter of $49 \mathrm{~nm}$ while the average diameter is $315 \mathrm{~nm}$ for the $84 \%$ particles larger than $150 \mathrm{~nm}$. Thus, the particle size of the present alloys is much smaller than that of platinum DPH and more beneficial for strength improvement.

\subsection{Particle strengthening at RT}

The critical stress to operate a Frank-Read source and to push a dislocation pass a barrier of nondeforming particles is related to the particle surface spacing ${ }^{[18]}\left(D_{A f}\right)$ expressed by the Orowan equation as follows: 
$\sigma_{Y}=\sigma_{00}+A \cdot \frac{G \cdot b}{2 \pi} \cdot \frac{1}{D_{A f}} \ln \left(\frac{D_{A f}}{b}\right)$,

where $\sigma_{Y}$ is the yield stress, $\sigma_{00}$ the stress required to generate and move dislocations in a matrix containing no particle. Other symbols are given in Table 3.

Since the particle shape is close to being spherical, the following equation is used to calculate $D_{A f}$, the surface to surface distance

$D_{A f}=d\left(\sqrt{\frac{\pi}{6} \cdot \frac{1}{f}}-\sqrt{\frac{2}{3}}\right)$,

The volume fraction of particles $\left(\mathrm{ZrO}_{2}\right)$ can be approximately calculated based on the weight fraction of $\mathrm{Zr}$ and the density of $\mathrm{ZrO}_{2}\left(5.69 \mathrm{~g} / \mathrm{cm}^{3}\right)$ and Pt-20Rh $\left(19.65 \mathrm{~g} / \mathrm{cm}^{3}\right)$.

The Orown stress $\left(\sigma_{o}=A \cdot \frac{G \cdot b}{2 \pi} \cdot \frac{1}{D_{A f}} \ln \left(\frac{D_{A f}}{b}\right)\right)$ with all $\mathrm{Zr}$ transformed into $\mathrm{ZrO}_{2}$ is given in Table 4 showing a significant contribution of particle strengthening to the flow stress both at RT and at $1000^{\circ} \mathrm{C}$.

There is also a contribution from a matrix stress determined by its thermal and mechanical history, and assumed to be the same for the four samples ${ }^{[19,20]}$. Thus, the particle $\left(\mathrm{ZrO}_{2}\right)$ parameter is the main variable for the specimens. The Orowan stress is then equal to the difference between the strength of samples (B, C and D) and sample A which is taken to represent the matrix strength. An experimental Orowan stress $\left(\sigma_{\text {exp }}\right)$ of sample B-D is then obtained by deducting the yield stress of the matrix (sample A) from the yield stress of B, C and D. Results are shown in Table 4 and for RT there is relatively good agreement between calculation and experiment, however a significantly higher deviation is observed at $1000{ }^{\circ} \mathrm{C}$.

The observation will be discussed in the following, based on the assumption that the calculated value of particle strengthening is an overestimate. One cause can be that a certain amount of $\mathrm{Zr}$ is present as solute atoms in the matrix and that the internal oxidation will be limited due to the extremely low solubility of oxygen atoms in the Pt-Rh alloy. The oxidation rate is difficult to measure accurately. But it can be estimated to be $75 \%$ according to the processing steps, see Tanaka Kikinzoku Kogyo K. K. ${ }^{[21]}$. Thus, the volume fraction of particles, the surface to surface spacing and the Orowan stress, are changed to $f_{75 \%}, \mathrm{D}_{A f 75 \%}$ and $\sigma_{o / 75 \%}$, respectively, to be recalculated. Results are shown in Table 5 and in Table 3. However, the solute atoms may cause lattice distortion and introduce solution strengthening, which is estimated based on the expression ${ }^{[22,23]}$ :

$\Delta_{s S}=M G b \varepsilon^{\frac{3}{2}} \sqrt{c}$ 
As an example, $\Delta_{S S}$ is about $2.4 \mathrm{MPa}$ with $0.3 \mathrm{wt} \% \mathrm{Zr}$ in solid solution, and thus solute solution strengthening is negligible. Based on Table 5 it is therefore concluded that there is a good accord between calculation and experiment based on superposition of Orowan strengthening and matrix strengthening with a difference between calculation and experiment in a range 11-23 MPa.

The presence of dispersed yttria may cause a small strength increase in the $\mathrm{ZrO}_{2}$ free matrix, which is neglected.

Table 3. The meaning and values of parameters used in the strengthening mechanism calculations.

\begin{tabular}{|c|c|c|c|}
\hline Symbol & Meaning & Value & Unit \\
\hline $\mathrm{A}$ & Constant & $\approx 1^{[18]}$ & \\
\hline $\mathrm{b}$ & Burgers vector & 0.276 at $\mathrm{RT}, 0.279$ at $1000{ }^{\circ} \mathrm{C}^{[24]}$ & $\mathrm{nm}$ \\
\hline G & Matrix shear modulus & 91.6 at $\mathrm{RT}, 69.8$ at $1000^{\circ} \mathrm{C}^{[25]}$ & $\mathrm{GPa}$ \\
\hline$d$ & Average diameter of particles & $\begin{array}{l}\text { 22, } 24 \text { and } 29 \text { for samples B, C and } \\
\text { D, respectively }\end{array}$ & $\mathrm{nm}$ \\
\hline$f$ & $\begin{array}{l}\text { Volume fraction of particles with all } \mathrm{Zr} \\
\text { present as } \mathrm{ZrO}_{2}\end{array}$ & $\begin{array}{l}0.0023,0.0042 \text { and } 0.012 \text { for } \\
\text { samples B, C and D, respectively }\end{array}$ & \\
\hline$f_{75 \%}$ & $\begin{array}{l}\text { Volume fraction of particles with } 75 \% \mathrm{Zr} \\
\text { present as } \mathrm{ZrO}_{2}\end{array}$ & $\begin{array}{l}0.0015,0.0031 \text { and } 0.0091 \text { for } \\
\text { samples B, C and D, respectively }\end{array}$ & \\
\hline$M$ & Taylor factor & $3.06^{\lfloor 22\rfloor}$ & \\
\hline$\varepsilon$ & $\begin{array}{l}\text { Radius difference between matrix and } \\
\text { solute }\end{array}$ & $11.5 \%$ for $\mathrm{Zr}$ as solute atom in $\mathrm{Pt}$ & \\
\hline$D_{A f}$ & $\begin{array}{l}\text { Planar particle surface to surface Distance } \\
\text { with all } \mathrm{Zr} \text { transformed into } \mathrm{ZrO}_{2}\end{array}$ & $\begin{array}{l}\text { 312, } 249 \text { and } 167 \text { for samples B, C } \\
\text { and D, respectively }\end{array}$ & $\mathrm{nm}$ \\
\hline $\mathrm{D}_{A f 75 \%}$ & $\begin{array}{l}\text { Planar particle surface to surface distance } \\
\text { with } 75 \% \mathrm{Zr} \text { present as } \mathrm{ZrO}_{2}\end{array}$ & $\begin{array}{l}\text { 363, } 290 \text { and } 196 \text { for samples B, C } \\
\text { and D, respectively }\end{array}$ & $\mathrm{nm}$ \\
\hline $\mathrm{D}_{A 75 \%}$ & $\begin{array}{l}\text { Planar particle spacing with } 75 \% \mathrm{Zr} \\
\text { transformed into } \mathrm{ZrO}_{2}\end{array}$ & $\begin{array}{l}381,310 \text { and } 220 \text { for samples B, C } \\
\text { and D, respectively }\end{array}$ & $\mathrm{nm}$ \\
\hline$c$ & Concentration of solute in weight percent & & $\%$ \\
\hline$k$ & Relaxation factor & $\approx 0.934^{[26]}$ & \\
\hline
\end{tabular}

Table 4. Comparison between calculated $\left(\sigma_{o}\right)$ and experimental particle strengthening $\left(\sigma_{0.2}-\sigma_{m}\right)$. $\sigma_{m}$ is the yield stress of sample A (matrix), $143 \mathrm{MPa}$ at RT and $67 \mathrm{MPa}$ at $1000{ }^{\circ} \mathrm{C}$. 


\begin{tabular}{ccccccc}
\hline & \multicolumn{2}{c}{ RT } & \multicolumn{3}{c}{$1000{ }^{\circ} \mathrm{C}$} \\
\hline Alloy & $\sigma_{o}$ & $\sigma_{0.2}$ & $\sigma_{0.2}-\sigma_{m}$ & $\sigma_{o}$ & $\sigma_{0.2}$ & $\sigma_{0.2}-\sigma_{m}$ \\
B & 91 & 200 & 57 & 68 & 89 & 22 \\
C & 110 & 228 & 85 & 83 & 99 & 32 \\
D & 154 & 257 & 114 & 117 & 124 & 57 \\
\hline
\end{tabular}

Table 5. Calculated and experimental particle strengthening with $75 \% \mathrm{Zr}$ present as $\mathrm{ZrO}_{2}$ at $\mathrm{RT}$ and at $1000^{\circ} \mathrm{C}$.

\begin{tabular}{cccccc}
\hline \multicolumn{3}{c}{$\mathrm{RT}$} & \multicolumn{3}{c}{$1000{ }^{\circ} \mathrm{C}$} \\
\hline Alloy & $\sigma_{o / 75 \%}$ & $\left(\sigma_{0.2}-\sigma_{m}\right) *$ & $\sigma_{o / 75 \%}$ & $\sigma_{P}$ & $\left(\sigma_{0.2}-\sigma_{m}\right)^{*}$ \\
$\mathrm{~B}$ & 80 & 57 & 60 & 24 & 22 \\
$\mathrm{C}$ & 96 & 85 & 73 & 30 & 32 \\
$\mathrm{D}$ & 135 & 114 & 102 & 44 & 57 \\
\hline
\end{tabular}

* See Table 4 .

\subsection{Particle strengthening at $1000^{\circ} \mathrm{C}$}

An Orowan stress at low temperature must be expected. However, at high temperature, dislocations may bypass the particles at a stress lower than Orowan stress, reaching a limit at a threshold stress below which the rate of deformation is negligible. A threshold stress is typically between 0.4 and 0.8 of the Orowan stress ${ }^{[26,27]}$. The reason is that dislocation can bypass the incoherent, nondeformable particles by glide and climb ${ }^{[26-29]}$, described by the Arzt-Rösler-Wilkinson (ARW) model and expressed in the following equation (Reppich ${ }^{[30]}$ )

$\sigma_{P}=0.9 M \frac{R^{3 / 2}}{2 \sqrt{2}+R^{3 / 2}}\left(G b / D_{A}\right)$

with $\mathrm{R}=2 \sqrt{1-k^{2}}$

The results of $\sigma_{P}$ are listed in Table 5, showing that the reduction in particle strengthening brings calculation and experiment in good accord.

\subsection{Outlook}

The assumption that the matrix stress for sample B, C and D can be represented by the behavior of sample A has not been tested experimentally. This is for future research based on EBSD characterization of microstructure and microstructural parameters. Further research is also in demand to measure the creep strength at high temperature of the dispersion strengthened samples to establish the threshold stress where the creep rate is negligible. 


\section{Conclusion}

Pt-20Rh dispersion strengthened by $\mathrm{ZrO}_{2}$ has been characterized by electron microscopy and tensile test at RT and $1000{ }^{\circ} \mathrm{C}$. The conclusions are the following:

1) The Pt-20Rh matrix is a recovered structure and divided by low angle dislocation boundaries and high angle boundaries, containing a uniform dispersion of $\mathrm{ZrO}_{2}$ particles with a size in the range 5-35 nm.

2) The flow stress ( $0.2 \%$ offset) increases with increasing volume percent of $\mathrm{ZrO}_{2}$ and is doubled at a volume fraction of $0.9 \%$ both at RT and $1000{ }^{\circ} \mathrm{C}$.

3) Based on a reformulation of the Orowan stress for particle strengthening and by superposing this stress to the matrix stress, a calculated flow stress is in good accord with the experimental value both at $\mathrm{RT}$ and at $1000{ }^{\circ} \mathrm{C}$ (Table 5).

\section{Acknowledgements}

Financial support from the Chongqing Science and Technology Bureau of China through Grant cstc2017zdcy-zdyfX0070 and cstc2018jszX-cyzdX0138 as well as the European Research Council (ERC) under the European Union's Horizon 2020 research and innovation program through Grant agreement No 788567 is gratefully acknowledged.

\section{References}

[1] J. Stokes, Platinum in the Glass Industry, Platin. Met. Rev. 31 (1987) 54-62.

[2] J. V. Pearce1, F. Edler, C. J. Elliot, A. Greenen, P. M. Harris, C. Garcia Izquierdo, Y. G. Kim, M. J. Martin, I. M. Smith, D. Tucker, R. I. Veltcheva, Systematic investigation of the thermoelectric stability of Pt-Rh thermocouples between $1300{ }^{\circ} \mathrm{C}$ and $1500{ }^{\circ} \mathrm{C}$, Metrologia, 55 (2018) 558.

[3] G. L. Selman, J. G. Day, A. A. Bourne, Dispersion Strengthened Platinum, Platin. Met. Rev. 18 (1974) 46-57.

[4] K. Maruyama, H. Yamasaki, T. Hamada, High-temperature creep of GTH, Mater. Sci. Eng. A 510 (2009) 312-316.

[5] M. Wenderoth, R. Volkl, T. Yokokawa, Y. Yamabe-Mitarai, H. Harada, High temperature strength of Pt-base superalloys with different $\gamma^{\prime}$ volume fractions, Scripta Mater. 54 (2006) 
275-279.

[6] B. Fischer, D. Freund, T. Brömel, R. Völkl, J. Daniel, W. Ross, R. Teschner, C. E. Michelsen, Practical Experience with New Oxide Dispersion Hardened Platinum Materials, $25^{\text {th }}$ International Precious Metals Conference, Tucson, Arizona, USA, June 9-12, 2001.

[7] S. K. Karak, T. Chudoba, Z. Witczak, W. Lojkowski, I. Manna, Development of ultra high strength nano- $\mathrm{Y}_{2} \mathrm{O}_{3}$ dispersed ferritic steel by mechanical alloying and hot isostatic pressing, Mater. Sci. Eng. A 528 (2011) 7475-7483.

[8] S. K. Karak, J. D. Majumdar, W. Lojkowski, A. Michalski, L. Ciupinski, K. J. Kurzydłowski, I. Manna, Microstructure and mechanical properties of nano- $\mathrm{Y}_{2} \mathrm{O}_{3}$ dispersed ferritic steel synthesized by mechanical alloying and consolidated by pulse plasma sintering, Philos. Mag. 92 (2012) 516-534.

[9] S. Bera, S. G. Chowdhury, W. Lojkowsky, I. Manna, Synthesis of CuCr and CuCrAg alloys with extended solid solubility with nano- $\mathrm{Al}_{2} \mathrm{O}_{3}$ dispersion by mechanical alloying and consolidation by high pressure sintering, Mater. Sci. Eng. A 558 (2012) 298-308.

[10] A. S. Darling, G. L. Selman, A. A. Bourne, Dispersion strengthened platinum, Platin. Met. Rev. 12 (1968) 7-13.

[11] Y. Dai, Q. Y. Ma, W. T. Liu, F. P. Hu, Y. Zhang, Z. L. Yang, H. Y, Tang, G. B. Wei, W. D. Xie, Effect of Zr on microstructure and mechanical property of dispersion-strengthened Pt-20Rh, Mater. Sci. Tech. 34 (2018) 654-659.

[12] J. C. Chaston, The oxidation of the platinum metals, Platin. Met. Rev. 19 (1975) 135144.

[13] D. Simeone, G. Baldinozzi, D. Gosset, M. Dutheil, A. Bulou, T. Hansen, Monoclinic to tetragonal semireconstructive phase transition of zirconia, Phys. Rev. B 67 (2003) 064111.

[14] P. Bouvier, E. Djurado, C. Ritter, A. J. Dianoux, G. lucazeau, Low temperature phase transformation of nanocrystalline tetragonal $\mathrm{ZrO}_{2}$ by neutron and Raman scattering studies, Int. J. Inorg. Mater. 3(2001) 647-654.

[15] T. Sakuma, Y. I. Yoshizawa, H. Suto, The microstructure and mechanical properties of yttria-stabilized zirconia prepared by arc-melting, J. Mater. Sci. 20 (1985) 2399-2407.

[16] B. Bondars, G. Heidemane, J. Grabis, K. Laschke, H. Boysen, J. Schneider, F. Frey, Powder diffraction investigations of plasma sprayed zirconia, J. Mater. Sci. 30 (1995) 16211625. 
[17] K. Teichmann, C.H. Liebscher, R. Völkl, High Temperature Strengthening Mechanisms in the Alloy Platinum - 5\% Rhodium DPH, Platin Met. Rev. 55 (2011) 217224.

[18] A. H. Clauer, N. Hansen, High temperature strength of oxide dispersion strengthened aluminum, Acta Metall. 32 (1984) 269-278.

[19] C. Y. Barlow, N. Hansen, Deformation structures in aluminum containing small particles, Acta Metall. 37 (1989) 1313-1320.

[20] K. Huang, K. Marthinsen, Q. Zhao, R. E. Logé, The double-edge effect of secondphase particles on the recrystallization behavior and associated mechanical properties of metallic materials, Prog. Mater. Sci. 92 (2018) 284-359.

[21] H. Yamazaki, Method for manufacturing strengthened platinum material, JP163069 (2005).

[22] K. Ma, H. Wen, T. Hu, T. D. Topping, D. Isheim, D. N. Seidman, E. J. Lavernia, J. M. Schoenung, Mechanical behavior and strengthening mechanisms in ultrafine grain precipitation-strengthened aluminum alloy, Acta Mater. 62 (2014) 141-155.

[23] T. Huang, L. Shuai, A. Wakeel, G. L. Wu, N. Hansen, X. X. Huang, Strengthening mechanisms and Hell-Petch stress of ultrafine grained Al-0.3\% Cu, Acta Mater. 156 (2018) 369-378.

[24] J. W. Arblaster, Crystallographic properties of platinum, Platin. Met. Rev. 41 (1997) $12-21$.

[25] J. Merker, D. Lupton, M. Töpfer, H. Knake, High Temperature Mechanical Properties of the Platinum Group Metals, Platin. Met. Rev. 45 (2001) 74-82.

[26] E. Arzt, D. S. Wilkinson, Threshold stresses for dislocation climb over hard particles: the effect of an attractive interaction, Acta Metall. 34 (1986) 1893-1898.

[27] E. Arzt, J. Rösler, The kinetics of dislocation climb over hard particles-II. Effects of an attractive particle-dislocation interaction, Acta Metall. 36 (1988) 1053-1060.

[28] E. Arzt, M. F. Ashby, Threshold stresses in materials containing dispersed particles, Scripta Metall. 16 (1982) 1285-1290.

[29] M. Nganbe, M. Heilmaier, Modelling of particle strengthening in the $\gamma$ 'and oxide dispersion strengthened nickel-base superalloy PM3030, Mater. Sci. Eng. A 387-389 (2004) 609-612.

[30] B. Reppich, On the attractive particle-dislocation interaction in dispersion- 
strengthened material, Acta mater. 46 (1998) 61-67 